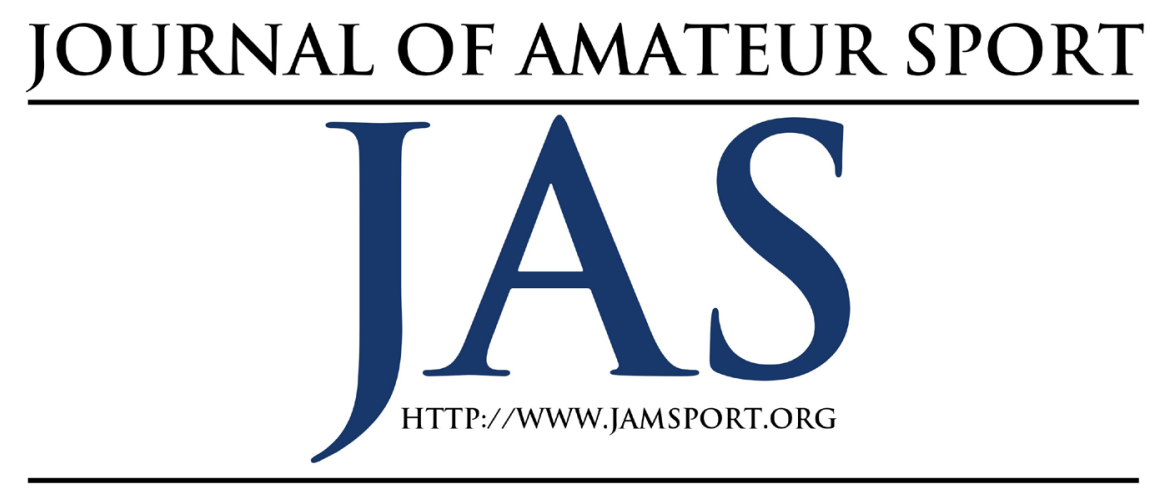

\title{
Investigating Student-Donor Memberships Within Collegiate Athletics
}

\author{
Austin C. Bogina ${ }^{1} \quad$ Brian S. Gordon ${ }^{2}$ \\ ${ }^{1}$ University of Central Missouri \\ ${ }^{2}$ University of Kansas
}

$1 \begin{aligned} & \text { cross the nation, intercollegiate } \\ & \text { athletic departments are con- } \\ & \text { structing new state-of-the-art }\end{aligned}$ facilities and offering premiere benefit packages to not only recruit potential student-athletes, but also for enhancing their fan support and engagement. However, due to the growing financial concerns occurring throughout the nation, National Collegiate Athletic Association (NCAA) Division I fundraising associates are beginning to explore new streams to generate additional revenue for their athletic departments (Popp, Barrett, \& Weight, 2016). Among NCAA Division I institutions, USA Today (2019) found that between 2018-2019, only $28 \%$ of the departments were able to generate over $\$ 50$ million in revenue. Due to the facilities arms race occurring in college athletics (Redd, 2018), athletic departments have to rely on their fundraisers now, more than ever, to implement new and innovative ways for obtaining the multi-million dollars in funding needed for their initiatives.

While prior research has acknowledged the connection between donor motivations and fan identification (Huml, Brown, \& Bergman, 2020; Huml \& Cintron, 2021), a dearth of empirical examination has been conducted on student-donor programs. Therefore, the value in this study rests in its key findings, which convey the details on the essential elements necessary for constructing a student-donor membership. Additionally, further key findings of this study provide value by answering the overall purpose these memberships aim to serve, which 
was found to be as pipelines to encourage continuous giving and as extensions of the annual fund.

The value of focusing specifically on student-donors resides in the fact that this younger generation will be the future target market for organizations, due to their higher earning years coming as they approach middle-age (Hall, 2014). Furthermore, the primary concern for college athletic departments neglecting to provide an option for younger donors to give, is that they instead place their attention on those with large disposable incomes because they can make the greatest immediate impact with a large donation (Leff, 2020). Additionally, one crucial detail that is often overlooked is the fact that the older donors become, the more likely it is that they choose to donate to multiple areas within the university, instead of giving solely to athletics (Martinez, Stinson, Kang, \& Jubenville, 2010; Stinson \& Howard, 2010a). In terms of the general donating behaviors displayed by different generations, when breaking down the number of charities each elects to donate to, Baby Boomers (born between 1947-1965) donate to an average of 4.2 charities, Generation X (born between 1965 and 1980) supports 3.8, and Millennials (born between 19811995) give to 3.5 charities (Otten, 2018). Interesting enough though, Generation Z (born after 1996) actually leads the way by supporting an average of 4.6 charities (Otten, 2018). This fact is why understanding donor memberships, as they apply to student-donors, is imperative to learn because failing to reach the young- er market may result in the process of restructuring fundraising and donations in collegiate athletics to be ineffective. Hence, this study attempts to fill a gap in the existing literature due to there being limited research conducted on student donor programs within collegiate athletics. Specifically, it aims to advance the research by Popp et al. (2016) on age of identification and donor behavior, Additionally, since no current research exists on how student-donors fit into the donor life cycle, the results of this study aim to provide essential knowledge on this highly important yet under examined group.

By exploring student-donor memberships, this study can contribute towards assisting in fundraising departments efforts as they attempt to encourage relationships to develop earlier on in their prospective donors' lives. Through this in-depth analysis of student-donor memberships, this study can also provide value to those collegiate athletic departments operating in the red, by serving as a new option to aid in their progression towards making their operations more profitable. Therefore, the purpose of this study was to discover the primary characteristics associated with offering student-donor (current college student) memberships within collegiate athletics. The secondary purpose for this study was to then detail the best practices acquired through in-depth interviews with associates in NCAA Division I athletic fundraising and development annual funds that would aid in developing a framework for how to properly implement a student-donor membership. 


\section{Literature Review}

The structure for this literature review covers several areas within the context of fundraising and development within collegiate athletics. Beginning with applying the relationship marketing theory to donor motivations, the reasons behind why someone elects to give financial support towards an organization will be presented. Next, by focusing on the varying donor demographics within collegiate athletics, connecting the existing theories with the primary motives will uncover whether commonalities can be applied across both current and potential new categories.

\section{Relationship-Marketing Theory}

To understand the foundation behind relationship marketing theory, Hennig-Thurau, Gwinner, and Gremler (2002) established that the concept is based on discovering the influential factors that lead to a party's ability to attain their desired outcomes, while also exploring the relationship between the motives and results. Within a collegiate athletic department, this concept can be seen through fundraisers building and supporting positive relationships between the organization and its valued donors. Mann (2007) stressed the importance of total communication between both parties because that is how an organization can do its part to guarantee overall satisfaction for those involved. In regard to understanding this theory, the two methods to consider are relational benefits approach and relationship quality approach (Hennig-Thaurau et al., 2002).
The relational benefits approach can be defined as the incentives a consumer receives from their commitment to a long-term relationship with a company or organization that goes above and beyond the core service performance (Gwinner, Gremler, \& Bitner, 1998). In applying this to a collegiate athletic situation, if a loyal, multi-year donor does not purchase their season football tickets before the deadline, the department may make an exception and allow them to still purchase the same seats that they have had in previous years thanks to their existing relationship. Bendapudi and Berry (1997) explained this approach in an even simpler manner by illustrating how the benefits that are received do not even have to be completely satisfying for the customer, as long as what they are receiving still outweighs the alternative of them not receiving it at all or going with a different option.

During a study focused on the relationship between customers and salespersons one main conclusion was found. According to Reynolds and Beatty (1999), positive perceptions of the benefits associated with a particular relationship occur in instances where mutual satisfaction exists between a customer and a salesperson. When there is a strong relationship between a customer and salesperson it results in satisfaction between the customer and the company as a whole. The significance in the findings of the Reynolds and Beatty (1999) study is due to it relating to the type of relationship that exists between donors (customer) and fundraisers (salesperson) 
or even between donors and the entire athletic department (company).

For the relationship quality approach, this concept focuses on addressing all of the necessary requirements that both parties have, which will then showcase a relationship that is both strong and progressive (Smith, 1998). Crosby, Evans, and Cowles (1990) found that this approach is structured on whether or not a salesperson is able to eliminate the initial hesitation that a customer may have before purchasing or renewing. With uncertainty, comes doubt which means that this method is designed to assure customers that there is no need for them to be concerned with undesired outcomes (Crosby, Evans, \& Cowles, 1990). Crosby (1991) discussed how the bond that is formed between both parties is created by how positively or negatively they interact, when and where they interact, and also their similarities that they both have as two separate entities. While a key aspect of this method is assuring consumers that their investment will be beneficial, fundraisers in collegiate athletes can approach the relationship knowing that the competition they face with the consumers they are targeting really only comes down to the person deciding whether or not to donate at all.

Yet, another way to understand this concept is through the departments that consistently produce winning programs and treat donors well, thus allowing them to capitalize on this aspect by both enticing new donors and also solidifying the existing ones for future years to come. In applying the relationship-marketing theo- ry to motivating donors within collegiate athletics, Hixon (2012) presented that the relationship is built, sustained, and strengthened to assure that the donor's satisfaction is always upheld. A focal point with this theory is to enhance the reputation of the organization through its ability to grow contributions as a result of its strong relationships with donors. Furthermore, Dorsch, Swanson, and Kelley (1998) stated how it should be expected for a relationship to exist based on a mutual understanding between parties that the goal is to both create a stronger relationship, while also improving the organization's status. Specifically, in scenarios where a donor increases their annual giving, then that should confirm the donor's intention of building a stronger relationship with the athletic fundraising department.

\section{Donor Types Standard Donor}

Research has shown that when it comes to the donor lifecycle that exists for individuals who give charitable gifts to universities, throughout the beginning of their post-college years there are few donations overall and those that do give donate gifts that are rather small (Tom \& Elmer, 1994). While looking into the progression of large donations, it typically occurs within 10 to 20 years after someone graduates, but it does still continue to grow between 20 to 30 years out (Tom \& Elmer, 1994). Tom and Elmer (1994) also discuss how once an individual reaches 40 years post-graduation, it becomes noticeable that there is a decline 
in their donations. Therefore, in illustrating the the ideal image of a collegiate athletic donor, Tsiotsou (2006) has been able to conclude that:

"Donors in athletics are married males from 40-60 years old, they are engaged in a profession or business, they are residents of the state, and they live within 200 miles of the campus. They are not yet retired, and over 65 percent of them have incomes exceeding $\$ 40,000$ per year" (p. 210).

In an extensive study on alumni and non-alumni donor motives, Gray (2009) found several common occurrences within the responses of participants. For starters, in two of three universities, non-alumni rated that improving the student-athlete's academic opportunities was their primary motivation, while the third school listed the opportunity to purchase tickets as theirs (Gray, 2009). Next, for the alumni respondents, their main motivation to give varied from improving the football program, improving the athletic department as a whole, and finally improving student-athletes academic opportunities (Gray, 2009).

Additionally, one of the lesser-known areas within this field that has yet to be fully studied is the factors that contribute to the separation of high versus low contributing donors (Humphreys \& Mondello, 2007; Sattler, Morehead, Popp, \& McEvoy, 2019). Regarding the relationship between seating preferences and donor level research has found that donor attendance at games did have some effect on giving level (Tsiotsou, 2006). Tsiotsou (2006) concurred that those attending games had more motivation to give much larger contributions than those who were not in attendance. Further, Stinson and Howard (2010b) found that nearly three-quarters of the donors that give charitable donations up to $\$ 5,000$ do so because that is the minimum amount that they can give to still be able to receive the primary seat locations they desire. For purchasing tickets to college athletic events, multiple studies have presented a relationship exiting between a donor's charitable gift and their preferred season ticket seating options (Coughlin \& Erekson, 1984; Mahony, Gladden, \& Funk, 2003; Humphreys \& Mondello, 2007; Huml, Brown, \& Bergman, 2020; Huml \& Cintron, 2021). This situation has been shown to operate as case of supply and demand, meaning that for successful athletic programs, the desire individuals have for the best seats is greater than the available seat options that facilities have, thus resulting in donors being required to make large donations to secure these prime locations (Coughlin \& Erekson, 1984; Mahony, Gladden, \& Funk, 2003; Humphreys \& Mondello, 2007). Furthermore, to fully grasp the magnitude of mega-donors to college athletic fundraising departments, it is important to understand The Rule of Thirds. According to Luy (2007), "This rule is the belief that one-third of your gifts will come from the top ten donors, the next one-third from the next top 100 donors, and the remaining gifts from all other donors." (p. 20).

In another study, Popp et al. (2016) differentiated between donor motivations that function in a transactional manner 
versus those that are transformational in nature. The former refers to individuals who are motivated by having the ability to receive tangible benefits for donating (Popp et al., 2016). Examples of individuals demonstrating being transactionally motivated would be those whose main reason for donating is to then purchase season tickets or parking passes. In terms of the latter, which the researchers reference as being altruistically motivated, this describes donors who are primarily concerned with whether their support is able to benefit others (Popp et al., 2016). Evidence of this type of donor motivation would be individuals who acknowledge their intent to donate for the purpose of enhancing the student-athlete experience and their well-being, with little-to-no attention being placed on what they will receive in return.

\section{Recent College Graduates}

While the level of interaction an individual had during their time attending a university is yet another donor characteristic that has been covered extensively, Terry and Macy (2007) presented an alternate approach. They discussed how the focus should instead be on graduates who feel a greater sense of commitment and responsibility towards the university due to having some form of involvement throughout numerous years post-college. Bass (2014) also explained that both loyalty and having a desire to progress the athletic department towards future success represented two of the main motivational factors for recent graduates. However, it should be known that no matter how involved an individual was while they were attending the university, one major factor has shown to negatively affect an individual's willingness to give back financially is the high level of debt some of them accumulated while they were students (Terry \& Macy, 2007; Baum \& O’Malley, 2003).

In building on the financial strain connected to the significant debt that recent graduates accumulated during college, the results from Baum and O'Malley's (2003) study showed that 40\% of respondents said they chose less-expensive schools or delayed their enrollment due to their financial restraint. The reason that this number is important for fundraisers to understand is because the financial stress that individuals with student loan debt have to deal with can cause them to feel as though it is not their duty to help the current students through donating, and instead want them to have to feel the weight of student loans themselves (Terry \& Macy, 2007).

While the debt factor has shown to negatively affect recent graduate donor potential, Meer (2013) again emphasized the fact that it is not about how much a recent graduate gives, it is about getting them in the mindset of simply giving a gift of any amount. What must be done when focusing on recent graduates is creating a habit of giving so that as they progress through the donor lifecycle, they transition from making small donations into giving larger ones (Meer, 2013). This idea ties into the belief that an individual's willingness to participate is a way of predicting their ability and 
desire to give later on in life (Turner, Meserve, \& Bowen, 2001). Sattler et al. (2019) further discussed the value in college athletic fundraising departments implementing crowdsourcing into their strategies used to discover new donors. In doing so, this was shown to offer fundraising associates a cost-effective method to reach and identify more prospective donors than would otherwise be possible through other standard tactics such as phone calls or emails (Sattler et al., 2019). Of additional value was that using crowdsourcing techniques to cultivate new donors provided these prospects with the freedom to give as little or as much of an initial gift as they could (Sattler et al., 2019). The idea behind using crowdsourcing as a donor cultivation technique is that it is a convenient way to identify individuals who show a willingness to give. This then allows a fundraising associate to cultivate a relationship that progresses towards transitioning the individual into the athletic department's donor pipeline.

\section{Methods}

\section{Research Setting and Procedures}

The authors utilized a qualitative methods research approach for data collection purposes. The choice to construct this study around a qualitative research approach allowed for interviews to serve as the main method for obtaining the necessary information from participants in the most effective and efficient manner. By utilizing this approach, the researchers were able to create thick descriptions of the unique feelings, thoughts, perceptions, and emotions of each participant (Jones \& Gratton, 2016). The decision to conduct interviews was based on the need to structure strategically prepared questions comprised from the advanced planning done by the researchers in an attempt to avoid obtaining inadequate results as well as due to the exploratory nature of the study and "newness" of the topic (Qu \& Dumay, 2011). To ensure the credibility of the participant responses, using one-on-one interviews also allowed for the interviewer to avoid interpreting responses by instead verifying the true meaning once it had been given (Kvale, 1988).

\section{Participant Selection}

To assist in further understanding how student-donor memberships throughout the nation are structured, 10 NCAA Division I, Power 5 athletic fundraising and development department student memberships were studied. Each of the 10 participants were selected from 10 separate athletic fundraising and development departments. The decision to interview 10 associates was based on the researchers reaching a point of saturation in regard to the responses being collected. Locating participants began by searching the official websites of athletic fundraising and development departments to discover which offered student-donor memberships. At the time data was collected, NCAA Division I athletic annual fund departments from the Southeastern Conference (SEC), Big Ten Conference (B1G), Big 12 Conference 
(Big XII), and Atlantic Coast Conference (ACC) were contacted. Of the departments who were successfully reached, 15 acknowledged currently offering a student-donor membership, 4 departments used to offer one, and 13 had never offered one at all. Regarding the 15 who did currently offer a student-donor membership, individual interviews were able to be scheduled with 10 of them. In terms of the specific departments represented within the sample, both the SEC and ACC had three representatives, while the B1G and Big XII were each represented by two departments.

The process for contacting participants was conducted through direct phone calls to each department and then once in contact with an associate, snowballing was applied for gaining additional leads on other potential participants. Furthermore, to qualify for this study, student memberships had to have been offered for at least two years. The reason behind this was to ensure that each department being interviewed would have the ability to reference multiple years of data. An additional requirement for participating in the interview was being an NCAA Division I fundraising and development associate, within the department, who had experience working closely with, or overseeing the student-donor membership. Due to the need for participants to be current NCAA Division I fundraising and development associates, the author used purposive sampling. Although the 10 participants held a variety of roles such as senior associate athletics director, director of development, as- sistant director of development, development officer, and graduate assistant, each of these individuals were selected based on them being the individual who worked the closest with their student-donor membership.

Regarding the primary archival data that was utilized within this study, athletic department websites were closely examined to assist in developing the initial baseline for understanding student-donor memberships. This data provided the researcher with surface-level view of the structure, benefits, and purpose of these memberships. More specifically, annual funds used their websites as a way to initially explain to prospective student-donors what the goal for the membership was, what tangible and experiential benefits they would receive by joining, and how much it would cost for them to become a member. Additionally, this data helped to inform the questions that were asked during the interview process.

\section{Interview Guide}

In regard to the questions used throughout the semi-structured interviews (see Appendix A for interview protocol), the ability for flexibility to be incorporated was done in an attempt to adhere to the potential varying responses provided by the participants. With the purpose of this study on discovering the primary characteristics associated with offering student-donor memberships within collegiate athletics, understanding the relationship (transactional vs. transformational) that exists between a department and their student members 
serves as a primary goal. Further, additional topics the interview focused on included the membership benefits that were offered, best platforms for communicating with members, recruitment tactics, branding and structuring strategies, membership fees, barriers and challenges, and finally, the goals that each department want to accomplish by offering a student membership. A voice recording was done for each interview, which allowed the author to transcribe the discussions. The interviews were conducted over the phone and lasted between 20-60 minutes. Each of the participants was then assigned a fictitious name to ensure that their identities remained anonymous.

\section{Data Analysis}

After the initial transcription of the interviews occurred, open coding allowed the authors to run through the interviews again, this time forming groups of similar concepts to generate new understandings for the student-donor membership phenomenon (Elo \& Kyngas, 2008). In addition to this, open coding permitted notes and headings to be incorporated while the authors transcribed the data from the interviews (Elo \& Kyngas, 2008). However, completion of the analysis for the study was not finalized until common themes had been agreed upon by the researchers. In addition to the phone interviews, secondary research was done by viewing the official website for each fundraising and development fund that participates in the study. This allowed the researchers to adhere to qualitative methodological guidelines by employing triangulation of data through the collection of multiple sources of data (Guba \& Lincoln, 1982; Lather, 1986), which included archival-type data and semi-structured interviews.

With credibility and dependability being critical standards to address in qualitative inquiry, ensuring that responses were recorded and transcribed correctly was completed through two measures: member checking and categorizing (Marshall \& Rossman, 2016). While direct quotes were regularly used during the interviews, the authors ensured that participants could not be identified through the published data (Elo \& Kyngas, 2008). In addition to the triangulation of data that was collected within this study, triangulation of interviewers was also used (Creswell \& Poth, 2018). Specifically, both researchers continuously participated in reflexivity and peer debriefing sessions to ensure that the developed themes and analysis were grounded in the data (Marshall \& Rossman, 2016). The researchers were both in agreement on each of the themes and subthemes presented within this study. To the best of each researcher's knowledge, the results of this study are valid, reliable, and should be further explored with confidence. By applying a qualitative research design, the findings presented within this study should also be viewed as transferable rather than generalizable to college athletic fundraising departments who are interested in offering a student-donor membership (Marshall \& Rossman, 2016).

\section{Results}

Following an analysis of the interviews, as well as the case study and archi- 
val data, the authors were able to categorize the findings into four common themes that will be explained in detail within this section. The four themes include: structure, benefits, communication, and branding.

\section{Structure}

For designing a student-donor membership, understanding the factors involved in structuring it for success consist of four key topics: purpose, who is involved, membership fee, and barriers/ challenges. The overarching idea behind this theme was to specifically outline the main areas that can determine whether student-donor memberships are designed for success. From developing the overall goal for the membership, to getting buyin among all associates within the department, selecting an affordable but appropriate membership fee, and eliminating potential threats to the membership, properly structuring a student-donor membership is the first step for funds interested in expanding the donor lifecycle.

Amongst the collegiate athletic departments that offer student-donor memberships, it is commonly recognized that the membership serves as the first step of a donor's lifecycle, representing a "pipeline" towards future larger donations. As fundraising and development departments continue to look for new ways to grow their donor membership bases, the value in offering student-donor memberships continues to grow. At the very least, through the student-donor memberships, fundraising and development departments are able to at gener- ate a base that will then serve as their future potential targets that they contact to become athletic annual fund donors. This idea of the membership serving as a "pipeline" is illustrated by the following quote, which was given by one associate but is representative of the responses given by other participants,

"It is a good way to see what may be coming down the pipeline. As far as what students' interests are, how involved they are at a younger age, and how long they are involved. It'll start with a $\$ 50, \$ 100$ gift and those can turn into the $\$ 10,000,000$ gifts down the line." Still, at the end of the day the price should be based on weighing what benefits are offered compared to the membership fee, which was emphasized by the following participant quote:

"Simple as looking at the price for what we are doing. Of course you want to do value received but we came to the conclusion that we want to be cheap, for lack of a better word, we want it to look easy, 'oh, it's only \$XX',"

In regard to deciding who should oversee and operate the student-donor membership, there are a few ideas to consider. While the student-donor membership should be housed within the athletic department, many associates still recognize that for it to be successful, it takes a team effort. Although many of the departments specifically assigned one to two associates to oversee the membership, several acknowledged that they still received outside help. By utilizing 
the Alumni Association and the athletic marketing department, this provides additional assistance in communicating with and offering benefits to the student-donor members. However, one fundraising associate explained their reasoning for keeping the athletic student membership internal as, "it was important to make sure that we distinguish our [Young Alumni] program, or the [student donor] membership compared to Alumni Association [Student Alumni] program." For differentiating between young alumni versus student donor programs, this can be done by understanding that the former pertains to donors who are recent college graduates, while the latter relates to donors who are current college students. By keeping the student-donor membership operated internally, fundraising and development departments can ensure that the membership is staying consistent with the goals and expectations of the regular athletics annual fund.

After analyzing the transcriptions and reviewing each annual fund's student-donor membership webpage, it was found that there is no "right" membership fee to charge for a student-donor membership. The range of the results varied from $\$ 15-\$ 100$, depending on the department. The mean for the membership price was $\$ 33.50$, while the median and mode was $\$ 25$. The fact of the matter is this is not a revenue generating membership. It is about engaging with, educating, and initiating student involvement with donating, so therefore the focus needs to be on finding a price affordable enough to where students will not hesitate to join. As one associate noted, “The (\$25) price point is obviously working for a lot of students. I don't think we have enough benefits right now to provide a reason to increase the membership price." The key takeaway is that by selecting a more affordable price, departments then have the ability to increase or decrease their fee once they have a better idea for how it aligns with the benefits they provide.

When deciding whether or not to offer a student-donor membership, college athletic fundraising and development departments should be aware of the barriers and challenges they may face. Being able to generate awareness and advance the membership stems from an annual fund's ability to successfully demonstrate their ability to stimulate student donors' willingness to pay for the student-donor membership, which is not an easy task. In terms of what one department sees as the biggest challenge they face, they discussed how it is crucial to address the perceived value of the student-donor membership. It falls on the fundraising and development associates to make the case for why students should be a member, as well as showing the significance in the student's decision to support the program. This issue was highlighted by the following representative participant quote,

"There's a lot of people competing for their time and their dollar. Think about all of the different student organizations that are on campus. Whether it's, fraternities/ 
sororities, and beyond that to different clubs and stuff. They have a lot of distractions. Why should they support this initiative? And I think you have to make a strong case for that, and that's tough."

The issue with overcoming the perceived value challenge is that this is a barrier a fund must face each year while a student is in college. However, an additional challenge funds face has been shown to occur internally within their own department, which was explained by the representative quote below,

"I think the biggest barrier is buy-in. You also need to have staff buy-in too, as in 'this is important and we need to sit down and get this done' whether it's something as simple as creating lists or whatever it is. The biggest issue too is having it as an afterthought."

\section{Benefits}

When it comes to deciding on the benefits that will be offered within a student-donor membership, it is important that what you provide also builds recognition amongst members, so they understand that their membership is a branch of the athletic annual fund.

\section{Transactional vs. Transformational.}

A key concept that student-donor memberships must decide between is having a transactional or transformational approach. In layman's terms, a transactional relationship is one where both parties understand exactly what will be provided in exchange for a specific donation amount (Transactional vs.
Transformational Giving, 2018). Alternatively, a transformational relationship is illustrated by a deeper-level connection being built between parties which in turn stimulates an emotional link resulting in increased trust and commitment to a cause (Transactional vs. Transformational Giving, 2018). Having a transactional approach refers to seeing the student-donor membership for what it is in the present: a student donating a small membership fee to receive a benefit that they otherwise wouldn't have access to. One fundraising associate highlighted the concept of a transactional approach within the following representative quote, "It's more transactional than transformational, because again, just to get them in the door and be members it does need to be a 'well what's in it for me?' type of build there." Another associate furthered this belief by stating,

"I don't think students are necessarily at the point in their lives to have $\mathrm{a}$, in their minds, a transformational impact giving at such a small level. I think it has to start transactional and that's how you build the relationship and eventually, if you do a good job in creating that relationship with transactional membership benefits, eventually it will turn into transformational." Specific examples of the transactional benefits used within the sample of college athletic student-donor memberships explored within this study have been explained in-detail throughout the following three subcategories. 


\section{Tangible Benefits.}

With many athletic annual funds having a transactional approach where students pay a membership fee for the sole purpose of receiving something in exchange, they must take this into account when selecting the benefits they will offer. Amongst most departments, the general consensus for a tangible item is a t-shirt and is emphasized by one fundraising associates' ability to turn this simple benefit into a collector's item. Within the following representative quote, an associate acknowledged that,

"Every year we are just switching colors around but the idea is you create a brand that you see people walking around in. There's a big ' 17 , big ' 18 , big ' 19 , whatever it is and you can collect each year." Another fundraising associate discussed how their department made sense of the decision to offer tangible benefits by explaining,

"You're always going to learn towards what nice, new, clean swag item can we give to incentivize kids to join this year or to renew their membership for the year? So I would say we lean heavily on an actual tangible benefit rather than like seating options, experience options."

\section{Experiences.}

Of the different student membership benefits, each of the participants acknowledged that their athletic annual fund focused heavily on the experiences that they could provide to students.
The reasoning for this is because most of these experiences do not cost them anything at all. It is about providing the students with the ability to have exclusive access to an experience that they otherwise would not be able to have. One associate indicated that,

"We do exclusive private practices with our head coaches. What that means is our students get to come into a behind-the-scenes look at an actual practice and we also try and try them a tour of the facility and get the behind-the-scenes look that a normal student wouldn't get. At the end of practice, they'll also have the opportunity to shake hands, take pictures with the head coach, and get that one-on-one experience."

With students, you need to provide them with something that helps them standout from their peers and numerous participants echoed the belief that a photo opportunity should be incorporated to make the experience even better.

\section{Priority Points.}

Priority points serve as a benefit that provides donors with the ability to accumulate points for their charitable giving amount, which then allows them to receive better incentives, such as season tickets or better seat locations. In regard to student memberships, one fundraising associate described their current situation as, "Each year before you graduate you can accumulate XX points and those priority points help to go along with your rank and your opportunity to purchase 
season tickets once you graduate." By having priority points as a benefit within a student membership, it begins transitioning the students into thinking of their overall donor rank, as well as how their points will translate into their future season-ticket seating location. This belief was shared by other participants and emphasized by the following representative quote,

"We do give our students priority points so that when they start their membership, they already start gaining points. So that's why we encourage them to start now because they transfer later on. This is the biggest thing that we do, which is why we have the number of members that we do."

\section{Communication}

For fundraising and development departments, communicating with their annual fund donors is far different from how they must reach both their current and potential student-donor members.

\section{Platforms.}

This concept can be summed up as "go where your audience is". Utilizing multiple platforms extends the range of who sees the messages and posts that are released. The following quote, provided by one associate, was representative of the other participants in this study regarding the primary communication platforms their departments utilize for connecting with student-donors, "We have Twitter, Instagram, and Facebook accounts and then once individuals give us their email to become members, we then have them on that list as well." However, while the previous response is from a heavy-user of communication tactics, athletic annual funds must still be selective on how frequently they reachout to their student members. Thus, another associate discussed how, "I try to leave it to twice a semester, as far as emails. I don't want to bog them down or ever come to the point where they want to hit "unsubscribe".

\section{Recruitment.}

In attempting to reach new students for joining a student-donor membership there are several approaches that departments have taken. The most successful method has been for fundraising departments to have a presence at Student Orientations that take place throughout the summer, which provide great opportunities to connect with a large number of incoming freshmen, as well as their parents. One associate reported that, "I work closely with the orientation leaders too. I'll talk about the [student donor] membership, and then when students or parents are asking 'hey, how can I get football season-tickets?' they can say 'here's how you do it, also don't forget to join the [student donor] membership".

Similar to the previous quote, another associate acknowledged their unique way of recruiting new student-donor members as, "Here with us we have a bunch of different student-run organizations, just like a lot of other universities. So 
our team is working on creating a liaison board between those other student organizations."

\section{Branding}

The final category to report on involves the strategies that NCAA athletic fundraising and development departments put into effect for branding their student-donor membership. For some, the focus has been on creating a brand that stands alone and functions separately from an athletic department's annual fund. Others, however, have realized the benefit in aligning the membership as a branch of the annual fund, which once again creates the idea of a "pipeline". As a result of these ideas, the authors were able to form two sub-categories: engagement and extension of the annual fund. The details pertaining to these concepts are further examined below.

\section{Engagement.}

For some student-donor memberships, branding it on the framework of supporting and being involved at athletic events has been a successful approach. This idea of having a place for students to be part of an exciting and interactive fan base is a common method to use and one associate explained it as, "a way to lock in those kids that are really passionate about supporting our teams, love it here on campus, being at the games, and having a loud presence." This mentality of emphasizing student-donor engagement by encouraging them to be active at events was further discussed by another participant who stated,
"During the summer, before students got on campus, I and three other staff members had a meeting and we basically came up with items or experiences that we thought would be fun for students. For example, we have a really great event before the basketball season starts. It is always packed and tough to get a seat. For that month, we decided to work with event management staff to reserve seats for (student-donors). We were ultimately trying to make them feel like VIPs."

\section{Extension of the Annual Fund.}

Designing a brand that can be recognized as an extension of the annual fund allows both current and potential student-donor members to understand the link between the two. For college athletic fundraising and development departments, this offers them an easy way to educate student-donors about the "pipeline" that exists between the student and annual membership. One fundraising associate acknowledged that,

"We ultimately wanted to go hand-in-hand with the [athletic annual fund]. Our logo and shield is the same that the [athletic annual fund] uses, it's just a different color and has our words in it. So the brand recognition is to make sure that our [student-donor membership] logo is on everything because if you've seen the [student-donor membership] logo then you'll recognize it or asso- 
ciate it with the regular [athletic annual fund] membership."

However, something to consider is that it is about building a brand that is consistent with the athletic annual fund, but still adding a creative aspect to meet the students' needs. This then strengthens the relationship between both parties and aligns directly with the relationship-marketing theory. The following quote described this strategy further and is representative of the perceptions shared by numerous participants,

"Our biggest brand point is we want to stay on brand with the actual [athletic annual fund]. We don't want them to feel like a different entity because they are still a part of the [athletic annual fund] family. So I think that if there were a difference it would be in tailoring the events that we do, the t-shirt we provide, to the actual college student."

\section{Discussion}

Two key findings in this study were on how athletic fundraising departments can benefit from and approach offering student-donor memberships to current college students. With the main reasons for annual funds to offer the student membership including "donor pipeline" and "student involvement", the focus should be on getting students active in the membership. In doing so, fundraising associates discover the individuals who have a willingness to donate, which they can build-on when the time comes to transition them into the annual fund. Although when it comes to measuring the profitability of a student membership, fundraising departments have to look at it long-term by considering the customer lifetime value associated with transitioning student-donors into the athletic annual fund. In terms of setting goals for the membership, even though student-donors do not contribute large amounts of revenue in the present it, is still important for fundraising departments to balance using the relationship marketing theory's relational benefits and relationship quality approach (Hennig-Thurau et al., 2002). To do this, associates should use the former to ensure that student-donor are satisfied with the benefits they receive by continuing to donate (relational benefits approach), while the latter can be used to further educate them on the impact that their donation is making on improving the quality of life for student-athletes (relationship quality approach). By acquiring both sets of information, this can help associates initiate personalized fundraising strategies that allow them to work toward building a lasting relationship with student-donors (Hennig-Thurau et al., 2002). Due to the participants within this study acknowledging that students demonstrate higher motivation for transactional versus transformational benefits, special attention should be placed on the relational benefits approach. For instance, the value in identifying a student-donor's key drivers would then allow for advancing their relationship with the fundraising department to occur through the process of "mutual satisfaction" (Reynolds \& Beatty, 1999). 
Regarding the specific challenges and barriers for structuring a student membership, the issues of generating awareness, getting in-house buy-in, and advancing the membership all connect to the need for associates to emphasize the perceived value of the membership. Due to fundraising associates being tasked with showing the value of the student membership, the situation relates back to the research on the relationship quality approach (Crosby et al., 1990). Within this approach, a salesperson works to eliminate the concerns of a potential buyer, while also meeting their requirements, which results in an agreement to purchase. Therefore, fundraising associates must reassure students that the price for the student membership, along with the benefits that they will receive, does outweigh what they are giving up outside of the membership. Kwon, Trail, and James (2007) also presented on the idea of measuring the perceived value of something by referencing an individual who goes through the process of comparing what they are giving up for what they are getting out of a purchase. More specifically, within their study the researchers calculated the likelihood of an individual buying licensed merchandise of a sports team as being determined by perceived value and the level to which they identified with the team (Kwon et al., 2007). How their findings can be applied to this study relates to the perceived value associated with purchasing a student-donor membership and the level of identification a prospective student-donor may have with an athletic program.
For those who identify highly with an athletic program, they may display higher motivation toward joining a student-donor membership, which would then allow for fundraising departments to cultivate a more personal relationship with the donor.

However, fundraising associates working with student-donor memberships are tasked with not only having to show student-donors the perceived value in monetary terms, but in nonmonetary terms as well (Gipp, Kalafatis, \& Ledden, 2008). What this means is that showing the perceived value in monetary terms applies to the donation a student-donor makes to receive a benefit, while the nonmonetary factor is in reference to the time and energy they must also give up. With their donation going toward them being able to receive a benefit, if the benefits that are offered also require a time commitment, such as attending an event, this then becomes a second perceived value barrier for prospective student-donors with busy schedules. Therefore, in accordance with the student-donor benefits participants within this study recommended using, offering a balance of tangible and experiential benefits would serve as an effective approach. In doing so, student-donors can receive tangible benefits that are of equal value to the membership fee they paid, such as a membership t-shirt and other merchandise, but also receive additional value through the experiential benefits they are invited to attend.

With the membership prices varying from $\$ 15-\$ 100$, the amount that received 
the most responses was $\$ 25$. One approach to validating the membership fee to students can be done by calling it a "discount" from the minimum donation required to be an annual fund donor (Lange \& Stocking, 2009). Also, by using the discount method, it can be beneficial towards getting students to view the student membership as a savings opportunity (Lange \& Stocking, 2009). To reiterate the feelings shared by participants and presented within the results of this study, the conversation surrounding selecting the appropriate membership fee should be based on choosing an affordable price that eliminates prospective student-donors initial hesitation to join. In addition to this, although participants discussed how the student-donor membership should operate under the athletic annual fund membership, they still encouraged departments to market its distinctiveness and benefits that align with student-donors specific needs and wants.

While the topic of single verses multi-level memberships has already been previously discussed (Cartwright \& Patel, 2013), both of the options are advised to offer at least a $\$ 25$ membership fee. Whether it is the only choice or the entry-level option for a multi-level approach, the $\$ 25$ fee coincides with the $\mathrm{t}$-shirt benefit, therefore allowing the exclusive experiences to serve as the true benefits members receive. For funds looking to create a multi-level membership, ensuring that you have benefits that justify there being multiple giving levels will ultimately decide whether or not this pricing option is successful. In regard to athletic departments that consistently reach bowl games and post-season tournaments, a fundraising associate interviewed within this study discussed how their first level receives a t-shirt, the second receives priority access to post-season football, and the third receives priority access for post-season basketball. Thus, funds should select a price cheap enough to eliminate hesitation (Crosby et al., 1990) from potential student-donors, while also renewing current members to keep them involved in the donor pipeline.

\section{Practical Implications}

Previously, when developing the framework for the lifecycle of a donor, it was not common practice for those in their first few years after graduating college to donate and even if they did, the donation would be small (Tom \& Elmer, 1994). Often times, a donor's progression towards making a significant donation wouldn't even occur until 10-20 years after they had graduated (Tom \& Elmer, 1994). Within this study, the approach used for understanding donor relations was done through the perspectives of fundraising associates. The value in using each perspective connects back to the peer-to-peer method for soliciting to donors (Grover, 2007), which can result in both parties being mutually satisfied (Reynolds \& Beatty, 1999). Resulting from the findings produced within this study, fundraising associates can confidently use this research as a guide for offering their own student membership, as well as how to build relationships with student-donors. 
When deciding between structuring a student-donor membership as transactional or transformational, the participants within study were in agreement that student-donors respond more positively towards the transactional approach. However, due to the emphasis on the annual fund being on the transformational benefits to donating, fundraising associates should still work to educate students on why their contribution matters. In building on having a transactional approach, it is beyond crucial to emphasize the "exclusiveness" factor of the benefits that are offered within the student-donor membership. The reasoning behind this is due to, in some cases, there being too many separate "fan groups" that exist within some athletic departments, instead of having one student-donor membership to unite them all.

In the case of Michigan State Athletics, they offer a non-branded student section for football, the "Izzone" for men's basketball, the "Munnsters" student section for hockey, the "Red Cedar Rowdies" for soccer, and "George's Jungle" for volleyball. The main concern with having five different "fan groups" is that three of them require a separate membership fee. It costs $\$ 183$ for the football student section, $\$ 55$ for the "Izzone", and an $\$ 85$ fee to be a part of the "Munnsters" (Michigan State Spartan Athletics, 2019). A separate t-shirt is provided through each paid membership but the "Izzone" fee only awards students the opportunity to purchase their home basketball tickets for an additional $\$ 10$ per game. While the football student sec- tion membership fee only goes towards home game tickets, "Izzone" members are invited to attend a campout and other group events through the basketball program, as well as having a shorter wait-time to enter the arena on game day. The only extra benefit for being a "Munnster" is that the t-shirt comes in the form of a jersey and members are invited to a pre-season event with the team. For the "Red Cedar Rowdies" and "George's Jungle", both of these student fan groups are free to all students and no additional benefits are provided.

The drawback to having separate student fan groups is that students have a lower disposable income, meaning they may have to choose which they want to join the most, as well as the absence of offering them consistent "exclusive" benefits that align with their membership fee. If an athletic annual fund was to instead offer one student-donor membership that included each sports student fan group, it would ensure that they are providing tangible and experiential benefits that showcase the exclusivity of the membership benefits students otherwise would not receive by not donating. Additionally, having separate student fan groups is a missed opportunity for generating long-term revenue due to athletic annual funds failing to cultivate a lasting relationship with these students who are demonstrating the proven donor motives of affiliation and socialization (Ko, Rhee, Walker, \& Lee, 2014).

For selecting the appropriate donor benefits, student-donor memberships should be built around offering exclu- 
sive experiences or priority access to home games/tickets. The first reason this approach should be followed is because these benefits do not cost the department anything. The second reason is that an experience has been shown to motivate students through public recognition (Degasperi \& Mainardes, 2017), therefore enhancing their association with the group (Schervish \& Havens, 1997). As for the experiences offered, these benefits will vary across athletic departments depending on whether or not they have facility tours or a popular coach that student want access to. For those who may not have a high-profile coach or facility, offering access to closed practices, sideline passes at games, graduation photos on the football field or in the basketball arena, and exclusive watch-parties were successful strategies used by participants within this study. However, even with the primary benefits being experience-related, the consensus among participants interviewed within this study was to provide students-donors with a membership t-shirt. As previously discussed, having the tangible benefit of a t-shirt is a simple way to give students something to have in exchange for their money. If the t-shirt has a unique design it can also help to generate awareness for the student membership and give students a way to identify with the group (Schervish \& Havens, 1997).

To connect these membership benefits and reflect on the reasoning for implementing a transactional approach for student-donor memberships, the idea for using this approach is to get as many current students as active as possible before they graduate. By also educating them on the philanthropic impact their gift makes, it then prepares them for the transformational approach that fundraising associates utilize once they transition into a recent graduate membership. Bass (2014) examined recent graduates and the results justified using the transformational approach on recent grads due to their desire to show loyalty, progress the athletic department, and provide educational benefits to student-athletes. However, while the results of this student-donor membership study show fundraising associates agreeing that current students are too young to understand their philanthropic impact, Bass (2014) found that those within five years post-graduation have already realized it. The significance of this information is that recent college graduates are developing their understanding for philanthropic giving long before reaching what has deemed as the most profitable, middle-age and financially stable, donor demographic. While student-donors and recent graduates operate as separate donor memberships, the major take-away for transitioning the approaches used on both memberships is that benefits for student-donors should build on enhancing their loyalty and commitment due to those being motivational factors for them as recent graduates.

For selecting the appropriate communication process of student-donor memberships, it should combine both old and new approaches. With emails continuing to serve as successful method 
for distributing information to members, a shift towards utilizing additional technology platforms can be beneficial (Shapiro, 2010). Students still receive emails from their university and check-in on the classes they are enrolled in, so this outlet remains relevant. A new approach should also utilize the social media platforms most used by students in an effort to "go where they are". Due to each platform serving a different purpose, knowing where to publish content can make a major impact on how it is received. For instance, with Facebook being focused on the "relationship" aspect provided through customized messages, Twitter allows for quick updates, conveniently located news stories, and interacting with followers (Voorveld, Van Noort, \& Muntinga, 2018). Additional platforms that should be utilized include Instagram, where users can share creative photo and video messages, as well as Snapchat, which can be used to release instant-photo and video messages (Voorveld et al., 2018). Regarding the demographics for users of social media platforms, research has shown that over $86 \%$ of 18 -29-yearolds use Facebook, over 67\% are on Instagram, over 38\% have Twitter, and $53 \%$ of those between the ages of 15-25 use Snapchat (Khoros, 2021). With the 18-24-year-old demographic being the age of college students, athletic annual funds now know what platforms to use. This will also help them make the right decision on where to post certain types of message to successfully reach their target audience for information regarding student-donor memberships. Still, yet another key communication factor that funds must pay more attention to is how they will recruit new members. With the consensus being on fundraising associates attending all freshmen orientations each summer, the reasoning for this is due to them being able to connect with a significant amount of potential new donors through in-person solicitation (Grover, 2007).

The final area associated with properly implementing a student-donor membership is on how to effectively brand it. By create the image of it being a way for students to be more closely involved with the athletic department; a mutually satisfying relationship can be built (Reynolds $\&$ Beatty, 1999). Those students wanting to have the full college experience of being a part of game-day activities and supporting their university, they can live out this dream by becoming a student-donor member. Furthermore, to build on the engagement factor of student memberships, marketing an image of the student-donors being involved at college athletic events will result them developing a positive brand recall. This idea was also addressed by Ross, James, and Vargas (2006) who explained brand recall occurring as a result of the perceived offerings a consumer associates with the brand. In other words, brand image can be created through the process a consumer goes through as they work towards understanding the significance of the brand (Ross et al., 2006). With an emphasis being placed on the engagement aspect of student-donor members, the tangible and intangible benefits that 
students receive through their participation can impact the brand image that they create.

The second way for branding the student membership is by aligning it directly as an "extension of the annual fund". Previous research has indicated that universities need to have a long-term approach to branding that is centered on the values and beliefs the organization as a whole has been built on (Whisman, 2009). According to Whisman (2009), corporate branding, as it pertains to student-donor memberships, creates a layout of all the experiences a donor could have as member. This action is consistent with the "extension of the annual fund" sub-category due to it highlighting an individual's experiences as a student-donor, as well as those they would have after transitioning to the annual fund. This can be done by having the student membership include a similar logo and message as the athletic annual fund to generate brand recognition by both current and non-members.

One additional approach to branding the student membership can be done though a mobile app on member's smartphones. This unique idea was explained by a fundraising associate as a way to have everything related to the student membership located in one convenient place. Membership applications, renewal deadlines, exclusive benefits, upcoming events, mobile ticketing, priority point ranking, and much more can all be accessed by student-donors through their personal donor account. It is through the process of students creating their donor account that fundraising depart- ments gain access to their contact info, which then allows for a direct release of information to be made to its intended audience. Gladden, Milne, and Sutton (1998) also stated that being able to generate strong brand awareness is the first step towards creating positive brand equity. Thus, by offering student-donors a one-stop-mobile-shop, branded by the athletic annual fund, could enhance their awareness of both memberships operating as one and the same.

\section{Limitations}

With this being a qualitative study, the results that it produced were acquired through purposive sampling, which relied on the data having to be interpreted by the author. Due to a lack of existing research done on college athletic donor memberships, connecting the findings to relative themes that also exist within athletic annual funds proved difficult. It is also not uncommon for limitations to occur within these types of studies due to participants having the ability to decide whether or not to share additional information regarding a specific question. Within this particular study, the issue of selecting what information to share was once again limited due to the sensitivity of the donor membership phenomenon that exists within college athletic fundraising and development departments. Although the researchers both agreed that including a participant table would be extremely helpful, after numerous attempts to create one that would be of value, it became clear that there was no way to do so without revealing the identities of participants. 
Unlike athletic annual funds, the limited number of student-donor memberships created a unique challenge. After discussing the participant table further, both researchers agreed that little effort would be needed to discover not only what departments were used, but a phone call or staff search would have revealed which specific individuals were interviewed. As a result of the sensitive nature of college athletic fundraising, several participants stressed the importance of ensuring that their identities remained confidential, so ultimately it was determined that providing a participant table would jeopardize the steps that were taken to maintain the confidentiality of each participant's identity.

\section{Considerations for Future Research}

This study added valuable insight into the front-end of the donor lifecycle as it can be used to further the previous research on athletic annual fund donors and donor memberships. From a fundraising perspective, two of the leading motives for making a donation to athletics are to purchase season tickets and better priority seating options (Coughlin \& Erekson, 1984; Humphreys \& Mondello, 2007). By athletic departments offering student section tickets at a cheaper price, it becomes even more important to investigate student donor memberships due to the primary ticketing and seating benefits having already been eliminated. Specifically, it is recommended that future research investigates the student-donors themselves, in an effort to discover the primary motives they share as influencing their willingness to give.
While the idea of a donor lifecycle had already been previously researched by Tom and Elmer (1994), the lifecycle that was created only touched on 10-, 20-, 30-, and 40-years post-graduation. In developing an approach to furthering this research, looking at the effects that beginning a donor's lifecycle while they are still attending the university have on their future donations would be one idea. The limitation to this study would be a result of many student-donor memberships still being relatively new, which means there could be minimal data available for athletic fundraising departments to speak on. Still, for investigating those who do have years of data on their student-donor membership to discuss, it would provide valuable insight into showing whether these memberships have a positive or negative effect on the transition process occurring within a donor lifecycle. Furthermore, the Tom and Elmer (1994) study also showed a decrease in donations occurring after 40 years post-graduation, so of additional value would be to determine whether the total years a donor donates is extended by starting their donor lifecycle early.

\section{References}

Bass, A. J. (2014). Recent graduate donor motivations (Order No. 1563929). Available from ProQuest Dissertations \& Theses Global. (1612427971). https://core.ac.uk/ download/pdf/210602085.pdf Baum, S., \& O’Malley, M. (2003). College on credit: How borrowers perceive their education debt. Journal of Student Financial Aid, 33(3), 7-19. 
Bendapudi, N., \& Berry, L. L. (1997). Customers' motivations for maintaining relationships with service providers. Journal of Retailing, 73(1), 15-37. doi:10.1016/s0022-4359(97)90013-0

Cartwright, E., \& Patel, A. (2013). How category reporting can improve fundraising. Journal of Economic Behavior \& Organization, 87, 73-90. doi:10.1016/j.jebo.2013.01.003

Coughlin, C. C., \& Erekson, O. H. (1984). An examination of contributions to support intercollegiate athletics. Southern Economic Journal, 51(1), 180. doi:10.2307/1058331

Creswell, J.W. and Poth, C.N. (2018) Qualitative inquiry and research design choosing among five approaches. 4th Edition, SAGE Publications, Inc., Thousand Oaks.

Crosby, L. A. (1991). Building and maintaining quality in the service relationship. Service Quality: Multidisciplinary and Multinational Perspectives, Stephen W. Brown and Evert Gummesson, eds. Lexington, MA: Lexington Books, 269-87.

Crosby, L. A., Evans, K. R., \& Cowles, D. (1990). Relationship quality in services selling: An interpersonal influence perspective. Journal of Marketing, 54(July), 68-81.

Dorsch, M. J., Swanson, S. R., \& Kelley, S. W. (1998). The role of relationship quality in the stratification of vendors as perceived by customers. Journal of the Academy of Marketing Science, 26(2), 128-142. doi:10.1177/0092070398262004

Elo S. \& Kyngas H. (2008). The qualitative content analysis process. Journal of Advanced Nursing, 62, 107-115. Gipp, N., Kalafatis, S. P., \& Ledden, L. (2008). Perceived value of corporate donations: an empirical investigation. International Journal of Nonprofit and Voluntary Sector Marketing, 13(4), 327346. doi:10.1002/nvsm.342

Gladden, J., Milne, G., \& Sutton, W. (1998). A conceptual framework for assessing brand equity in division I college athletics. Journal of Sport Management, 12(1), 1-19.

Gray, P. M. (2009). An examination of annual athletic-fund donor motivations (Order No. 1467269). Available from ProQuest Dissertations \& Theses Global. (304962434). Retrieved from https://cdr.lib.unc.edu/concern/dissertations/8c97kq77t

Grover, S. R. (2007). Successful strategies for capital campaigns. Community College Journal, 77(6), 28-31. Retrieved from https://www2.lib. ku.edu/login?url=https://www. proquest.com/trade-journals/successful-strategies-capital-campaigns / docview/207591321/se-2?accountid $=14556$

Guba, E., \& Lincoln, G. (1982). Epistemological and methodological bases of naturalistic inquiry. ECTJ, 30(4), 233-252. https://doi.org/10.1007/ BF02765185

Gwinner, K. P., Gremler, D. D., \& Bitner, M. J. (1998). Relational benefits in services industries: The customer's perspective. Journal of the Academy of Marketing Science, 26(2), 101-114. doi:10.1177/0092070398262002

Hall, H. (2014, September 21). Cultivating young donors holds promis- 
ing return, survey finds. Retrieved from https:/ / www.philanthropy. com/article/Cultivating-Young-Donors-Holds/152621

Hennig-Thurau, T., Gwinner, K. P., \& Gremler, D. D. (2002). Understanding relationship marketing outcomes. Journal of Service Research, 4(3), 230-247. doi:10.1177/1094670502004003006

Hixon, N. (2012). Million dollar plus donors within intercollegiate athletics: A qualitative analysis of donor motivations (3588291) (Doctoral dissertation). Retrieved from ProQuest Dissertations and Theses database. (3588291)

Huml, M. R., Brown, K. M., \& Bergman, M. J. (2020). A deficiency of donors or an abundance of barriers? Title IX fundraising challenges from the perspective of athletic department fundraisers. Journal of Intercollegiate Sport, 13(1), 48-68. https://doi. org/10.17161/jis.v13i1.13304

Huml, M., \& Cintron, A. (2021). Stakeholder status in the identification, prioritization and management of college athletic donors. Sport, Business and Management: An International Journal. ahead-of-print. doi:10.1108/SBM-09-2020-0085.

Humphreys, B. R., \& Mondello, M. (2007). Intercollegiate athletic success and donations at NCAA division I institutions. Journal of Sport Management, 21(2), 265-280. doi:10.1123/ jsm.21.2.265

Jones, I., \& Gratton, C. (2016). Research methods for sports studies. New York, NY: Routledge.
Khoros. (2021, June 15). The 2021 social media demographics guide. Khoros | Digital care, communities, \& social media software. https://khoros. com/resources/social-media-demographics-guide

Ko, Y., Rhee, Y., Walker, M., \& Lee, J. (2014). What motivates donors to athletic programs: A new model of donor behavior. Nonprofit and Voluntary Sector Quarterly, 43(3), 523-546.

Kvale, S. (1988). The 1,000 page question. Phenomeno1o + Pedago', 6(2), 90-106

Kwon, H. H., Trail, G., \& James, J. D. (2007). The mediating role of perceived value: Team identification and purchase intention of team-licensed apparel. Journal of Sport Management, 21(4), 540-554. doi:10.1123/ jsm.21.4.540

Lange, A., \& Stocking, A. (2009). Charitable memberships, volunteering, and discounts: Evidence from a largescale online field experiment. NBER Working Paper No. 14941. Available at: https://www.nber.org/system/ files/working_papers/w14941/ w14941.pdf

Lather, P. (1986). Issues of validity in openly ideological research: Between a rock and a soft place. Interchange, 17(4), 63-84. https://doi. org $/ 10.1007 /$ bf01807017

Leff, J. (2020, December 21). College sports facing long-term threats of aging fan and donor demographics. Sportico.com. https://www.sportico. com/leagues/college-sports/2020/ donor-demographics-college-sports-1234618741/ 
Luy, D. (2007). Athletic fundraising at NCAA division III colleges and universities [ProQuest Dissertations Publishing]. http:// search.proquest. com/docview/304715484/

Mahony, D., Gladden, J., \& Funk, D. (2003). Examining athletic donors at NCAA Division I institutions. International Sports Journal, 7(1), 9-27.

Mann, T. (2007). College fund raising using theoretical perspectives to understand donor motives. International Journal of Educational Advancement, 7(1), 35-45. doi:10.1057/palgrave. ijea. 2150042

Marshall, C., \& Rossman, G.B. (2016). Designing qualitative research (6th ed.). Thousand Oaks, CA: Sage.

Martinez, J., Stinson, J., Kang, M., \& Jubenville, C. (2010). Intercollegiate athletics and institutional fundraising: A Meta-Analysis. Sport Marketing Quarterly, 19(1), 36-47.

Meer, J. (2013). The habit of giving. Economic Inquiry, 51(4), 2002-2017. doi:10.1111/ecin.12010

Michigan State Spartan Athletics. (2019). Student sections. Retrieved from https://msuspartans.com/ sports/2018/7/20/studentsections. aspx

Otten, L. (2018, June 28). Giving by generation - different giving preferences by generation. Retrieved from https://www.lasallenonprofitcenter. org/generational-charitable-giving/

Popp, N., Barrett, H., \& Weight, E. (2016). Examining the relationship between age of fan identification and donor behavior at an NCAA divi- sion I athletics department. Journal of Issues in Intercollegiate Athletics, 9, 107123.

Qu, S. Q., \& Dumay, J. (2011). The qualitative research interview. Qualitative Research in Accounting \& Management, 8(3), 238-264. doi:10.1108/11766091111162070

Redd, D. (2018, July). College athletics arms race shows no signs of slowing. Athletic Business. https://www.athleticbusiness.com/college/collegeathletics-arms-race-shows-no-signsof-slowing.html

Reynolds, K. E., \& Beatty, S. E. (1999). Customer benefits and company consequences of customer-salesperson relationships in retailing. Journal of Retailing, 75(1), 11-32. doi:10.1016/s0022-4359(99)80002-5

Ross, S. D., James, J. D., \& Vargas, P. (2006). Development of a scale to measure team brand associations in professional sport. Journal of Sport Management, 20(2), 260-279. doi:10.1123/jsm.20.2.260

Sattler, L., Morehead, C., Popp, N., \& McEvoy, C. (2019). Click here to donate: An examination of online crowdfunding campaigns by division I intercollegiate athletic departments. Journal of Issues in Intercollegiate Athletics, 12, 454-478.

Schervish, P. G., \& Havens, J. J. (1997). Social participation and charitable giving: A multivariate analysis. Voluntas, 8(3), 235-260. doi:10.1007/ bf02354199

Shapiro, S. L. (2010). Does service matter? An examination of donor per- 
ceptions of service quality in college athletics. Sport Marketing Quarterly, 19(3), 154-165. https://core.ac.uk/ download/pdf/217287889.pdf

Smith, J. B. (1998). Buyer-Seller relationships: Similarity, relationship management, and quality. Psychology and Marketing, 15(1), 3-21. doi:10.1002/ (sici)1520-6793(199801)15:1<3::aidmar2>3.0.co; $2-\mathrm{i}$

Stinson, J., \& Howard, D. (2010a). Athletic Giving and Academic Giving: Exploring the Value of SPLIT Donors. Journal of Sport Management, 24, 744-768.

Stinson, J., \& Howard, D. (2010). Intercollegiate athletics as an institutional fundraising tool: An exploratory donor-based view. Journal of Nonprofit \& Public Sector Marketing, 22(4), 312-335. doi:10.1080/10495140802662572

Terry, N., \& Macy, A. (2007). Determinants of alumni giving rates. Journal of Economics \& Economic Education Research, 8(3), 3-17.

Tom, G., \& Elmer, L. (1994). Alumni willingness to give and contribution behavior. Journal of Services Marketing, 8(2), 57-62. doi:10.1108/08876049410058442

Transactional vs. Transformational Giving. (2018). The Major Gifts Report, 20(12), 3-3. https://doi. org/10.1002/mgr.31096
Tsiotsou, R. (2006). Investigating differences between female and male athletic donors: a comparative study. International Journal of Nonprofit and Voluntary Sector Marketing, 11(3), 209223. doi:10.1002/nvsm.34

Turner, S. E., Meserve, L. A., \& Bowen, W. G. (2001). Winning and giving: Football results and alumni giving at selective private colleges and universities. Social Science Quarterly, 82(4), 812-826. doi:10.1111/00384941.00061

USA Today. (2019). NCAA finances 2018-2019 finances. Retrieved from https://sports.usatoday. $\mathrm{com} / \mathrm{ncaa} /$ finances/

Voorveld, H. A., Van Noort, G., Muntinga, D. G., \& Bronner, F. (2018). Engagement with social media and social media advertising: The differentiating role of platform type. Journal of Advertising, 47(1), 38-54. doi:10.1080/0091 3367.2017 .1405754

Whisman, R. (2009). Internal branding: A university's most valuable intangible asset. Journal of Product \& Brand Management, 18(5), 367-370. 


\section{Appendix A}

\section{Interview Protocol}

1.) When was the membership program started?

a. Why was it started?

b. How has it evolved?

2.) How did you develop the benefits that would be offered within a student-donor membership?

a. How do you decide between or balance the tangible items v. experiences?

3.) How did you arrive at your price point?

4.) How do you communicate with student-donors?

a. What platforms do you utilize?

5.) What is your approach/strategy for recruiting new members?

6.) Discuss how you developed the branding for the student-donor membership.

7.) When structuring a student-donor membership, what are the most important factors to consider?

a. Who should oversee it? (internal, student organization, Alumni Association)

8.) What are the barriers or challenges associated with implementing a student-donor membership?

9.) Would you say your student-donor membership is more transactional (exchange) or transformational (relational)?

10.) What are you looking to achieve with the student-donor membership?

a. What are your goals/outcomes?

b. How are they measured? 